\title{
Источник спин-поляризованных электронов на основе мультищелочного фотокатода
}

\author{
В. С. Русецкий ${ }^{1,2}$, В. А. Голяшов ${ }^{1}$, А. В. Миронов ${ }^{2}$, А. Ю. Дёмин ${ }^{2}$, О. Е. Терещенко \\ ${ }^{1}$ Институт физики полупроводников им. А. В. Ржанова СО РАН \\ 630090, пр. Академика Лаврентьева, д. 13, Новосибирск. \\ ${ }^{2} 3$ АО Экран ФЭП, 630060 ул. Зеленая горка, д. 1, Новосибирск \\ эл. почта: vadim19230495@yandex.ru
}

DOI 10.34077/RCSP2021-115

В настоящее время проводится большое количество исследований, направленных на создание эффективных источников и детекторов спин-поляризованных электронов. Источники спинполяризованных электронов находят применение в ускорителях частиц, а также в спинполяризованной электронной микроскопии. Существующие источники спин-поляризованных электронов изготавливаются на основе материалов А3В5 и позволяют получать пучок с высокой поляризацией (более 90\%) [1,2]. Однако, такие источники электронов сильно подвержены влиянию остаточной атмосферы вакуумной камеры и, следственно, обладают малой долговечностью. Для получения неполяризованных пучков электронов часто используют фотокатоды на основе антимонидов щелочных металлов (как правило $\mathrm{Cs}_{3} \mathrm{Sb}, \mathrm{Cs}_{2} \mathrm{KSb}, \mathrm{CsK}_{2} \mathrm{Sb}$ ) [3,4]. Данные фотокатоды проще в изготовлении, дешевле и менее восприимчивы к остаточной атмосфере вакуумной камеры. Однако, данных по фотоэмиссии спин-поляризованных электронов из таких фотокатодов не найдено.

Данная работа посвящена изучению фотоэмиссии спин-поляризованных электронов из мультищелочного фотокатода $\left(\mathrm{Na}_{2} \mathrm{KSb}: \mathrm{Cs}-\mathrm{Sb}\right)$ и возможности его использования в качестве источника спин-поляризованных электронов.

Для изучения процессов эмиссии и инжекции спин-поляризованных электронов были изготовлены вакуумные фотодиоды, в которых мультищелочные фотокатоды использовались в качестве источников электронов, а гетероструктуры А3В5 - в качестве спин-детектора. Ранее, на примере фотодиодов с гетероструктурами А3В5 нами было показано, что такая конструкция удобна для изучения эмиссионных и инжекционных свойств материалов [5,6].

Проведен сравнительный анализ измеренных зависимостей степени поляризации фотолюминесценции (ФЛ) для GaAs и мультищелочного фотокатода от энергии возбуждающего изучения $(1.58-3.05$ эВ) и толщины фотокатода. Максимальная степень поляризации ФЛ оказалась равной $22 \%$ для мультищелочного фотокатода и $18 \%$ для GaAs фотокатода при энергии возбуждающего излучения равной 1.58 эВ при комнатной температуре. Данные о поляризации ФЛ в мультищелочных фотокатодах были получены впервые. Получены спектральные зависимости степени поляризации ФЛ в мультищелочном фотокатоде в зависимости от температуры при энергии возбуждающего излучения равной 1.58 эВ. В исследуемых образцах мультищелочных фотокатодов обнаружена смена знака поляризации ФЛ с понижением температуры, что, вероятно, связано с расщеплением подзон лёгких и тяжёлых дырок в валентной зоне. Подобный эффект используется в гетероструктурах A3В5 для получения пучков электронов с высокой степенью поляризации (> 90 \%) $[1,2]$. Обнаружение поляризованной ФЛ, связанной с эффектом оптической ориентации, позволило предположить возможность эмиссии спин-поляризованных электронов в вакуум. Впервые нами была измерена степень поляризации катодолюминесценции в гетероструктуре $\mathrm{Al}_{0.1} \mathrm{Ga}_{0.9} \mathrm{As}$ при инжекции спин-поляризованных электронов из мультищелочного фотокатода. Таким образом, показана возможность получения пучков электронов, поляризованных по спину, из данного типа фотокатодов.

Работа выполнена при финансовой поддержке РФФИ в рамках научного проекта № 20-32-90152.

\section{Лumepamypa}

[1] X. Jin, et al. // Appl. Phys. Express 6. 015801 (2013).

[2] T. Maruyama, et al. // Nucl. Instrum. Meth. A 492. 199-211 (2002).

[3] N. Nishimori, et al. // Particles 1(1). 166-174 (2018).

[4] J. L. McCarter, et al. // Proceedings of 2011 Particle Accelerator Conference, New York, NY, USA (2011).

[5] V.A. Golyashov, et al. // Ultramicroscopy 218. 113076 (2020).

[6] O. E. Tereshchenko, et al. // J. Synchrotron Rad 28. 864-875 (2021). 